\title{
The Impact of Deindustrialization on Economic Growth-—Evidence from China
}

\author{
Yang Feng ${ }^{1}, \&$ Yang Wang ${ }^{1}$ \\ ${ }^{1}$ Central University of Finance and Economics, School of Economics, Beijing 100081, China \\ Correspondence: Yang Feng, Central University of Finance and Economics, School of Economics, Beijing \\ 100081, China.
}

Received: March 19, 2021

Accepted: April 5, $2021 \quad$ Online Published: April 13, 2021

doi:10.5539/ibr.v14n5p18

URL: https://doi.org/10.5539/ibr.v14n5p18

\begin{abstract}
Deindustrialization is a widespread phenomenon, both in developed economies or developing countries in the history. This paper examinate the impact of deindustrialization, which is caused by administrative measures aimed at overcapacity, on China's economic growth in the lastest decade. We adopt empirical approach to estimate the impact, the results show deindustrialization have a significantly negative effect on economic growth in the central and western China, which is stronger in the cites with fast deindustrialization, and in medium and small cities. It provides evidence that rapid deindustrialization hinders the sustainability and magnifies the vulnerability of economic growth, especially premature deindustrialization.
\end{abstract}

Keywords: deindustrialization; economic growth; industrial structure

\section{Introduction}

In recent decades, both developed and developing countries are in a deindustrialization trend, which means the share of industry in economic activities is significantly downward (Rodrik, 2016). Actually, in development economics theory, industrialization refers to the process of economic modernization driven by industrial sector and sustained growth of per capita income (Clark, 1940; Chenery, 1960; Kuznets, 1971). Due to the change of demand structure for different products, it leads to the change of industrial structure (Kongsamut et al, 2001). The reason for acceleration of deindustrialization is probably relatively high productivity growth rates in manufacturing industry taken by technology, e.g., automation, which takes a rising share of relatively technologically stagnant sector, i.e., service industry (Baumol, 1967; Nordhaus, 2008; Acemoglu and Restrepo, 2018a \& 2018b). Meanwhile, in the process of deindustrialization, it displaces workers from jobs with high wages in manufacturing industry into employment with relatively less payment in service industry, a less optimistic picture emerges lower income and decreasing consumption demand may lead to descending economic growth (Feenstra et al., 1996; Ebenstein et. al, 2017).

Furthermore, when the expansion of financial and business activities squeezes manufacturing industry, it arouses crowding-out effect and overcapacity problem and evolves into deindustrialization, or even premature deindustrialization in developed and developing countries (Liu et al.,2020). In order to ensure the stability of China's economy, the central government issues the four-trillion-yuan stimulus package (Chen et al., 2020), with the rapid growth of M2 (Chen and Zha, 2018). Owing to inputting a large portion of the capital into several manufacturing industries and leading overcapacity in some industries, e.g., steel and iron, China focuses on axing the overcapacity in following years, which causes fast deindustrialization and declining economic growth, corresponding to the period from 2010 to 2016 in Figure 1. Figure 2 demonstrates that the deindustrialization is widespread across China, especially in the central, western and northeastern China. However, in contrast with the level of economic development in Figure 3, we find that most of cities with fast deindustrialization are not developed areas, on the contrary, they are relatively undeveloped and far away from the coast, which means they do not have export advantage compared with cities in the eastern region. We could imagine that when cities leave the support of manufacturing industry with a limited per capita income, whether service industry could promote economic growth? In this paper we investigate the impact of deindustrialization on economic growth in China, it is insightful to understand the negative effect of fast deindustrialization on economic growth, which provides evidence that premature deindustrialization harms economic growth and fills the gap in the existing literature. In the rest of the paper, section 2 describes the data in the empirical estimation, section 3 presents the 
empirical strategies and results, section 4 concludes main evidences in the paper, and provides suggestions for upgrading the industrial structure and promoting economic growth.

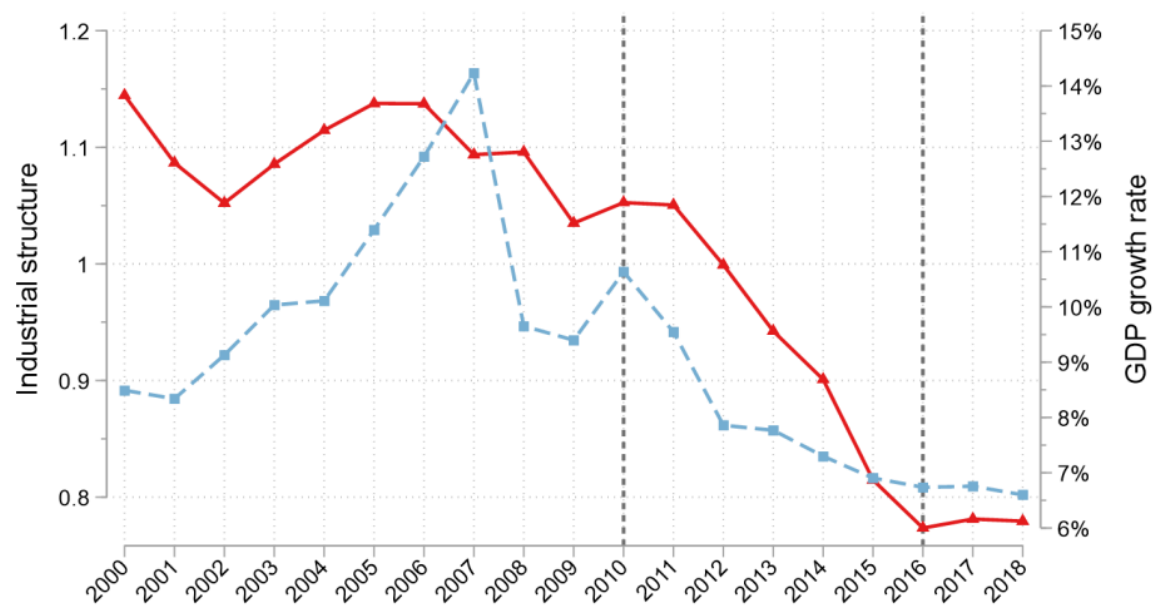

Figure 1: Deindustrialization and Economic Growth in China

$\leadsto$ Ratio of value-added between industry and service industry $\quad \Rightarrow$ GDP growth rate

Source: World Development Indicators

Figure 1. Deindustrialization and Economic Growth in China

Indicator: Ratio of value-added between secondary and teriary industry ar prefecture-level cities

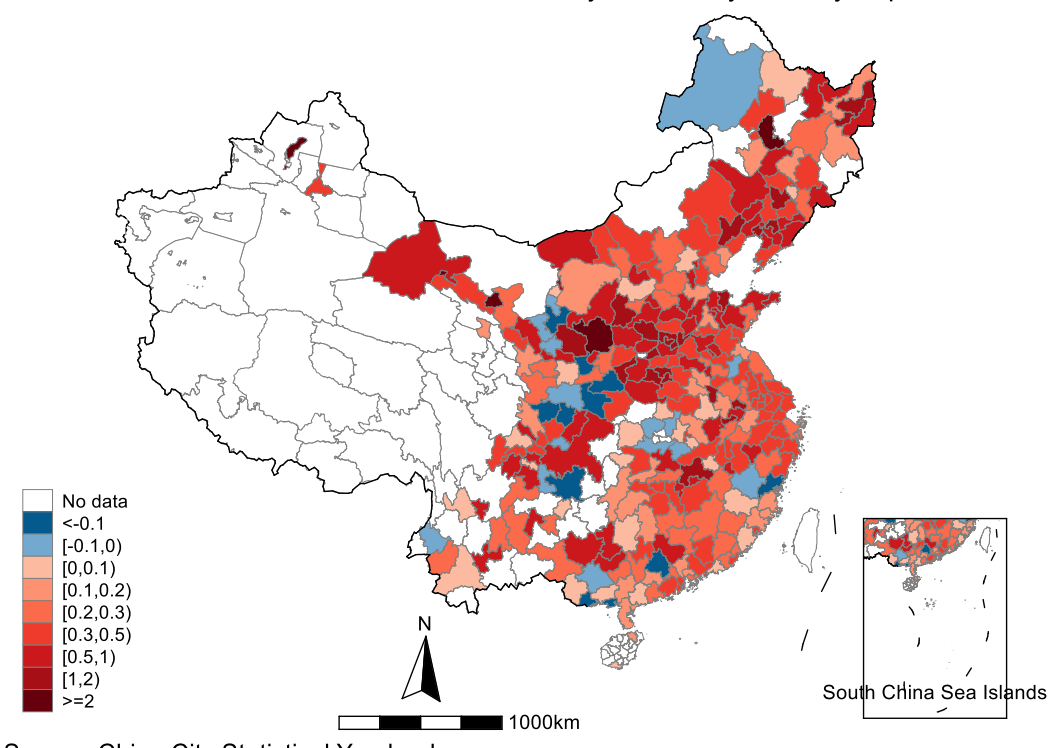

Source: China City Statistical Yearbook

Figure 2. Deindustrialization across China, compared 2010 with 2016 


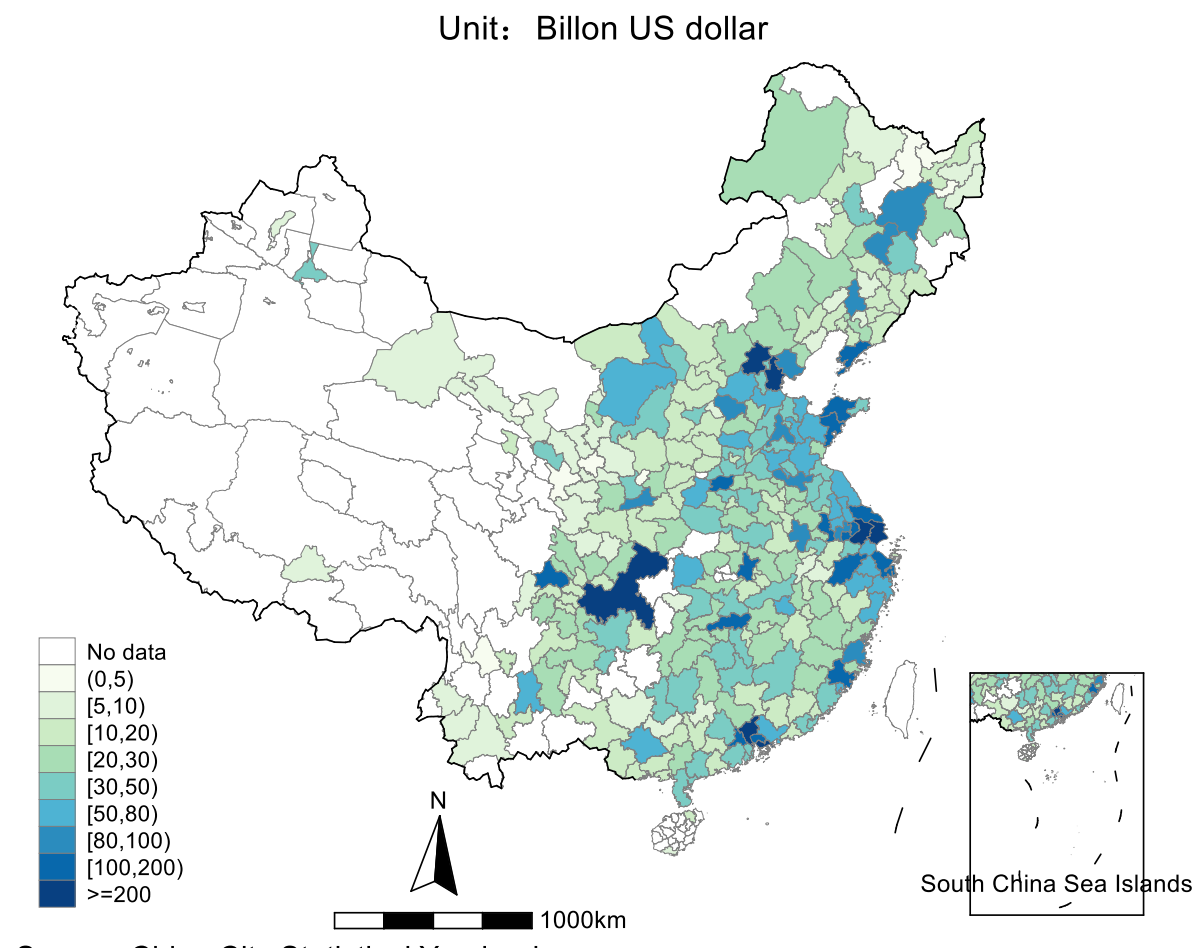

Source: China City Statistical Yearbook

Figure 3. Prefecture-level cities's GDP across China in 2016

\section{Data}

In order to examine the impact of deindustrialization on economic growth, we use prefecture-level city data to conduct empirical research for two reasons. First, industrial policies related to deindustrialization are usually formulated by the central government, provincial governments are followed the policies and establish specific arrangements to prefecture-level cities or below. Since the pillars of a prefecture-level city are usually limited industries, while there may be several dominant industries at provincial level or above, the variation of deindustrialization will be more obvious at prefecture-level city level. Second, within a prefecture-level city, manufacturing industries are usually mainly distributed in several districts or counties around main urban area, the official and living districts or counties are less affected by deindustrialization policies, it is not proper to observe the deindustrialization at county levels or below. Above all, we carry out empirical estimations on the impact of deindustrialization on economic growth by the sample of prefecture-level cities.

Our data comes from China City Statistical Book, including characteristic variables such as GDP, industrial structure, population density and so on. The sample covers 282 prefecture-level cities, including most prefecture-level cities in China, which is enough representative. The sample period is from 2010 to 2016, corresponding to the obvious stage of China's deindustrialization in Figure 1.

Consistent with the above, we measure the ratio of value- added of secondary industry and tertiary industry as an indicator of the industrial structure, and use the difference of industrial structure between the previous year and this year as the variable for deindustrialization speed. When the variable is positive, it reflects the decline of secondary industry in the economy, which indicates that the economy is in a state of deindustrialization, and larger the variable is, it means a faster deindustrialization speed.

As a classic variable of economic growth, we take the logarithm of GDP of prefecture-level cities as the variable to measure the rate of economic growth. In addition, we add a series of characteristic variables, e.g., investment, government scale, population scale and employment factors, to control possible impacts on economic growth. Table 1 presents descriptive statistics of the variables in the following empirical estimations. 
Table 1. Descriptive Statistics

\begin{tabular}{lrrr}
\hline Variable & Observation & Mean & Std.Dev. \\
\hline GDP (billion US dollar) & 1981 & 33.858 & 45.305 \\
Deindustrialization speed & 1975 & 0.031 & 0.104 \\
Ratio of fix-asset investment and GDP & 1979 & 0.776 & 0.277 \\
Ratio of government expenditure and GDP & 1981 & 0.075 & 0.053 \\
Population density (persons in per square kilometer) & 1698 & 434.409 & 335.44 \\
Employment in urban units (10 thousand persons) & 1980 & 56.865 & 85.902 \\
Employment in private enterprises and self-employed & 1931 & 55.141 & 78.531 \\
individuals (10 thousand persons) & & & \\
\hline
\end{tabular}

\section{Empirical Strategies and Results}

In order to estimate the impact of deindustrialization on economic growth, we exploit the variation of deindustrialization speed between prefecture-level cities through ordinary least square (OLS) method. Section 3.1 presents baseline estimation results. To ensure the robustness of baseline estimation results, we carry out robustness checks at section 3.2, by excluding cities with higher administrative levels, to observe whether baseline estimation results have changed. Furthermore, we adopt a instrument variable (IV) estimation strategy at section 3.3 to eliminate the endogenous problem, e.g., reverse causality, according to similar pressures of deindustrialization of cities located in the same province. At last, section 3.4 presents heterogeneous impacts on different groups between regions, deindustrialization speed and population scale.

\subsection{The Baseline Estimation Results}

Our baseline specification follows the form below,

$$
\ln \left(G D P_{i t}\right)=\alpha \cdot \text { deind }_{i t}+X \beta+\lambda_{i}+\varphi_{j t}+\varepsilon_{i t}
$$

where the outcome variable $G D P_{\text {it }}$ is GDP in year $t$ in city $i$. The explanatory variable $\operatorname{deind}_{\mathrm{it}}$ is the deindustrialization speed in year $t$ in city $i$, which equals the difference between the ratio of value-added of secondary industry and tertiary industry in year $t-1$ in city $i$ and the same indicator in year $t$ in city $i . X$ are a series of characteristic variables in year $t$ in city $i$, in order to control possible factors affecting economic growth. The parameter $\lambda_{i}$ estimate city fixed effects, and $\varphi_{j t}$ estimate province-specific year fixed effects for province $j$ in year $t$, where city $i$ locates in province $j$. The error term $\varepsilon_{i t}$ is clustered at the city level to control possible serial correlation within a prefecture-level city. Based on the above specification, we use OLS method to investigate the impact of deindustrialization on economic growth.

Table 2. Baseline estimation results

\begin{tabular}{|c|c|c|c|}
\hline \multirow[b]{2}{*}{ Variables } & \multicolumn{3}{|c|}{$\ln (\mathrm{GDP})$} \\
\hline & (1) & (2) & (3) \\
\hline \multirow[t]{2}{*}{ Deindustrialization speed } & $-0.2465 * * *$ & $-0.1601 * * *$ & $-0.1339 * * *$ \\
\hline & $(0.0517)$ & $(0.0455)$ & $(0.0368)$ \\
\hline \multirow[t]{2}{*}{ Ratio of fix-asset investment and GDP } & & -0.0128 & -0.0180 \\
\hline & & $(0.0279)$ & $(0.0268)$ \\
\hline \multirow[t]{2}{*}{ Ratio of government expenditure and GDP } & & -0.1158 & $-0.4685 * * *$ \\
\hline & & $(0.1692)$ & $(0.1486)$ \\
\hline \multirow[t]{2}{*}{$\ln$ (Population density) } & & & $0.1561 * *$ \\
\hline & & & $(0.0669)$ \\
\hline \multirow[t]{2}{*}{$\ln$ (Employment in urban units) } & & & 0.0304 \\
\hline & & & $(0.0198)$ \\
\hline \multirow{2}{*}{$\begin{array}{l}\ln \text { (Employment in private enterprises and } \\
\text { self-employed individuals) }\end{array}$} & & & 0.0026 \\
\hline & & & $(0.0061)$ \\
\hline Constant & $\begin{array}{l}3.1167 * * * \\
(0.0016)\end{array}$ & $\begin{array}{l}3.1003 * * * \\
(0.0252)\end{array}$ & $\begin{array}{c}2.0868 * * * \\
(0.3989)\end{array}$ \\
\hline Observations & 1,975 & 1,940 & 1,628 \\
\hline Adjusted R-squared & 0.9910 & 0.9956 & 0.9970 \\
\hline City Fixed Effects & $\mathrm{X}$ & $\mathrm{X}$ & $\mathrm{X}$ \\
\hline Province-specific Year Fixed Effects & $\mathrm{X}$ & $\mathrm{X}$ & $\mathrm{X}$ \\
\hline City Number & 283 & 278 & 277 \\
\hline
\end{tabular}

Standard errors are clustered at the city level. *, ** and *** denote significance levels of $10 \%, 5 \%$ and $1 \%$ respectively. 
Table 2 presents the baseline estimation results by OLS method. Column (1) shows the results according to baseline specification function by controlling for city fixed effects and province-specific year fixed effects only. Column (2) includes investment and government factors further, by controlling for the ratio of fix-asset investment and GDP and the ratio of government expenditure and GDP. Column (3) includes the additional population and employment factors, by controlling for the logarithm of population density, employment in urban units and employment in private enterprises and self-employed individuals. According to column (3), we find that the estimated coefficient for deindustrialization speed is -0.1339 , which means, when the economy is in a state of deindustrialization, every 0.1 unit for the decline of the ratio of value-added of secondary industry and tertiary industry, GDP growth rate of cities will drop nearly 1.34 percent. Combined with the situation in Figure 2, deindustrialization has an important impact on the decline of China's economic growth.

\subsection{Robustness Check}

In China's developing structure, cities with higher administrative levels usually have more resources and tend to be more developed on economic growth. Compared with other cities, these cities with higher administrative levels have already entered the post-industrialization, the portion of value-added of industry in GDP is already low, and most of manufacturing industries are high-tech industries. Therefore, economic growth of these cities is unlikely to be influenced by deindustrialization policies aimed at overcapacity. This situation probably leads to underestimate the coefficient of deindustrialization speed on economic growth. To eliminate this bias, we choose to exclude cities with higher administrative levels as robustness check, as presented in Table 2.

Column (1) in Table 2 excludes province-level municipalities (i.e., Beijing, Shanghai, Tianjin and Chongqing). Column (2) further excludes sub-provincial cities, which contains municipalities with independent planning status under national social and economic development (e.g., Shenzhen), these cities are usually economic centers in the provinces respectively. Column (3) excludes additional provincial capital cities, which is the administrative center of each province. The coefficients of deindustrialization speed in Table 2 are statistically significant at $1 \%$ level, which means our baseline estimation results are robust. At the same time, we notice that the coefficients are above 0.1339 , which means the negative impact of deindustrialization on economic growth are more distinct for cities with lower administrative levels, which are usually medium or small cities. From the results in Table 2, we find that deindustrialization will increase the economic gap between developed and developing regions.

Table 2. Robustness checks: excluding cities with higher administrative levels

\begin{tabular}{lccc}
\hline Variables & \multicolumn{1}{l}{$\ln (\mathrm{GDP})$} & $(3)$ \\
\hline Deindustrialization speed & $(1)$ & $(2)$ & $-0.1446 * * *$ \\
& $-0.1632 * * *$ & $(0.0481)$ \\
Observations & $(0.0459)$ & $(0.0465)$ & 1,732 \\
Adjusted R-squared & 1,942 & 1,851 & 0.9945 \\
City Fixed Effects & 0.9956 & 0.9947 & $\mathrm{X}$ \\
Province-specific Year Fixed Effects & $\mathrm{X}$ & $\mathrm{X}$ & $\mathrm{X}$ \\
City Number & $\mathrm{X}$ & 265 & 248 \\
\hline Standard errors & 278 & Xre clustered at the city & \\
\hline
\end{tabular}

Standard errors are clustered at the city level. *,** and $* * *$ denote significance levels of $10 \%, 5 \%$ and $1 \%$ respectively.

\subsection{Instrument Variable Estimation Results}

After the baseline estimation and robust checks, we show that deindustrialization speed has a significant negative effect on economic growth. However, we worry about whether this relationship is affected by omitted variable, or reverse causality, e.g., cities with descending economic growth may choose to adjust industrial structure by deindustrialization. Therefore, we explore an IV estimation strategy to eliminate the possible bias taken by endogenous problem.

Due to China's deindustrialization policies are mainly aimed at overcapacity industries, and the target of deindustrialization policies is usually assigned by province, we construct an IV according to similar pressure of deindustrialization for cities in the same province. Based on Chinese industrial enterprises database (Brandt et al., 2012), we rank cities within each province and calculate the ratio of gross industrial output value of 2-digit 
overcapacity industries ${ }^{1}$ of each city in the province. We create the IV by measuring the average deindustrialization speed of cities with similar rankings, here we define the scope as two ranking above or below for the target city. If average deindustrialization speed of cities with similar rankings is faster, deindustrialization pressure of the city is lower. Table 3 present the IV estimation results by two steps least square (2SLS) method.

Column (1) and (2) in Table 3 report the results of first and second step of IV estimation. The coefficient of IV in column (1) is -0.3820 and statistically significant at $1 \%$ level, which means deindustrialization speed of cities with similar rankings are faster, it will relieve the pressure of deindustrialization for the target city. The coefficient in column (2) is nearly 2.5 times of the magnitude in baseline estimation, which is probably caused by local average effect, because of the measurement error are not likely to influence the estimation results so much. Kleibergen-Paap F statistic is large than 10, which commonly exclude the possibility of weak instrument. Column (1) presents the OLS estimation result by adding the IV into baseline specification, we find that the IV is statistically insignificant at $10 \%$ level, which indicates the IV is not affect economic growth directly, which reinforces the validity of IV estimation.

Table 3. IV estimation results

\begin{tabular}{|c|c|c|c|}
\hline & $\begin{array}{c}\text { Deindustrialization } \\
\text { speed }\end{array}$ & $\ln (\mathrm{GDP})$ & $\ln (\mathrm{GDP})$ \\
\hline & OLS & 2 SLS & OLS \\
\hline Variables & $(1)$ & $(2)$ & (3) \\
\hline Deindustrialization speed & & $\begin{array}{c}-0.3316^{* *} \\
(0.1527)\end{array}$ & $\begin{array}{c}-0.1256 * * * \\
(0.0380)\end{array}$ \\
\hline IV & $\begin{array}{c}-0.3820 * * * \\
(0.0863)\end{array}$ & & $\begin{array}{c}0.0787 \\
(0.0606)\end{array}$ \\
\hline Observations & 1,628 & 1,628 & 1,628 \\
\hline Adjusted R-squared & 0.6769 & -0.0960 & 0.9970 \\
\hline City Fixed Effects & $\mathrm{X}$ & $\mathrm{X}$ & $\mathrm{X}$ \\
\hline Province-specific Year Fixed Effects & $\mathrm{X}$ & $\mathrm{X}$ & $\mathrm{X}$ \\
\hline City Number & 277 & 277 & 277 \\
\hline Kleibergen-Paap F statistic & & 19.589 & \\
\hline
\end{tabular}

\subsection{Heterogeneity Analysis}

At last, we present heterogeneity analysis by comparing different groups by regions, deindustrialization speeds and population scales. First, we explore whether the impact of deindustrialization on economic growth differ across regions in China, as presents in Table 4. We divide cities by the eastern, central and western China, the estimation results as shown in column (1), (2) and (3) respectively. We find that the effect of deindustrialization on economic growth is insignificant in cities of eastern China, while the effects are statistically significant at $1 \%$ level in the central and western regions, and the coefficients are even larger. It indicates the negative impacts of deindustrialization on economic growth are mainly concentrated in cities of central and western China, where are relatively undeveloped regions. Undoubtedly, it will widen the gap of regional economic growth in China further.

\footnotetext{
${ }^{1}$ In this paper, we define the overcapacity industries as the list below, which include Mining and washing of coal (06), Mining and processing of ferrous metal ores (08), Mining and processing of non-ferrous metal ores (09), Mining and processing of nonmetal ores (10), Smelting and processing of ferrous metals (31), Smelting and processing of non-ferrous metals (32), Manufacture of metal products (33) and Manufacture of railway, ships, aerospace and other transportation equipment (37).
} 
Table 4. Heterogeneity analysis I: dividing cities by regions

\begin{tabular}{lccc}
\hline & & $\ln (\mathrm{GDP})$ & \\
& Eastern & Central & Western \\
Variables & $(1)$ & $(2)$ & $(3)$ \\
\hline Deindustrialization speed & -0.0073 & $-0.1768^{* * *}$ & $-0.2600^{* *}$ \\
& $(0.0491)$ & $(0.0613)$ & $(0.0988)$ \\
Observations & 682 & 686 & 574 \\
Adjusted R-squared & 0.9970 & 0.9927 & 0.9928 \\
City Fixed Effects & $\mathrm{X}$ & $\mathrm{X}$ & $\mathrm{X}$ \\
Province-specific Year Fixed Effects & $\mathrm{X}$ & $\mathrm{X}$ & $\mathrm{X}$ \\
City Number & 98 & 98 & 82 \\
\hline Sty & & & \\
\hline
\end{tabular}

Standard errors are clustered at the city level. *,** and *** denote significance levels of $10 \%, 5 \%$ and $1 \%$ respectively.

Second, we examine heterogeneity effects of different deindustrialization speeds on economic growth, the estimation results as presented in Table 5. Column (1) shows the result of subsample with faster deindustrialization speed, e.g., we set the condition of deindustrialization speed is larger or equal to 0.1 , and column (2) reports the result of the else cities. Interestingly, we find that cities with faster deindustrialization are suffered more severe economic downturn. By contrast, economic growth rate of the subsample with slower deindustrialization declines slightly, the coefficient is statistically significant at $10 \%$ level and the magnitude is only one seventh of the former. From the estimation results in Table 5, it provides evidence that industrial structure adjustment should be moderate, aggressive deindustrialization may cause more serious effect on economic growth.

Table 5. Heterogeneity analysis II: dividing cities by deindustrialization speeds

\begin{tabular}{|c|c|c|}
\hline \multirow[b]{3}{*}{ Variables } & \multicolumn{2}{|c|}{$\ln (\mathrm{GDP})$} \\
\hline & Cities with faster deindustrialization & $\begin{array}{l}\text { Cities with slower } \\
\text { deindustrialization }\end{array}$ \\
\hline & (1) & \\
\hline Deindustrialization speed & $\begin{array}{c}-0.4342 * * * \\
(0.1042)\end{array}$ & \\
\hline Observations & 156 & 1,353 \\
\hline & 0.9951 & 0.9985 \\
\hline & $\mathrm{X}$ & X \\
\hline Year Fixed Effec & $\mathrm{X}$ & $\mathrm{X}$ \\
\hline City Number & 73 & 277 \\
\hline \multicolumn{3}{|c|}{$\begin{array}{l}\text { Standard errors are clustered at the city level. *,** and } * * * \text { denote significance levels of } 10 \%, 5 \% \text { and } 1 \% \\
\text { respectively. }\end{array}$} \\
\hline \multicolumn{3}{|c|}{$\begin{array}{l}\text { Third, we investigate whether the effect of deindustrialization on economic growth are different in cities with } \\
\text { different population scales. We divide the sample into big cities group and medium and small cities group, which } \\
\text { take the population scale of } 5 \text { million as the standard. The coefficient of column (1) in Table } 6 \text { shows that the } \\
\text { negative impact of deindustrialization on economic growth is insignificant in big cities, while the effect is } \\
\text { significant in medium and small cities, as shown in column (2). Due to diversified consumption demand of huge } \\
\text { population scale, the contribution of manufacturing industry on GDP growth is not such important in big cities. } \\
\text { However, the residents in medium and small cities are extremely relied on the job opportunities and wages of } \\
\text { manufacture enterprises, that explains why the negative effect of deindustrialization on economic growth is only } \\
\text { significant in medium and small cities. }\end{array}$} \\
\hline
\end{tabular}


Table 6. Heterogeneity analysis III: dividing cities by population scales

\begin{tabular}{|c|c|c|}
\hline \multirow[b]{2}{*}{ Variables } & \multicolumn{2}{|c|}{$\ln (\mathrm{GDP})$} \\
\hline & $\begin{array}{l}\text { Big cities } \\
\text { (1) }\end{array}$ & $\begin{array}{c}\text { Medium and small cities } \\
\text { (2) }\end{array}$ \\
\hline Deindustrialization speed & $\begin{array}{l}-0.0028 \\
(0.0298)\end{array}$ & $\begin{array}{c}-0.1727 * * * \\
(0.0467)\end{array}$ \\
\hline Observations & 516 & 1,039 \\
\hline Adjusted R-squared & 0.9984 & 0.9948 \\
\hline City Fixed Effects & $\mathrm{X}$ & $\mathrm{X}$ \\
\hline Province-specific Year Fixed Effects & $\mathrm{X}$ & $\mathrm{X}$ \\
\hline City Number & 92 & 182 \\
\hline
\end{tabular}

Standard errors are clustered at the city level. *,** and *** denote significance levels of $10 \%, 5 \%$ and $1 \%$ respectively.

\section{Conclusion}

This paper investigates the impact of deindustrialization on economic growth in China, according to the empirical estimation and IV method. We find that deindustrialization in the latest decade significantly induces the decline of economic growth rate, which is robust after excluding cities with higher administrative levels and adopting IV estimation. In the heterogeneity analysis, we find the negative effects of deindustrialization on economic growth are mainly concentrated in the cities of central and western China, and also stronger in the cities with fast deindustrialization and small population scale.

After the Industrial Revolution, manufacturing industry is the important engine of economic growth, and promoting economic growth of developed and developing countries through international trade and industrial transfer. However, with the expansion of financial and business activities, manufacturing is losing its dominance in the economy. As new technologies are emerging, rapid deindustrialization, especially premature deindustrialization, is challenging the durability of economic growth and industrial structure, which leads decreasing demand and rising skill requirement for workers. If income is not enough to support individual's consumption and human capital investment, the economy will be vulnerable and unsustainable in the long term. Governments should pay more attention on these potential problems caused by deindustrialization. The real economy is the foundation of the development of virtual economy, when the inflation of the virtual economy is faster than the development speed of the real economy, it will squeeze the development space of the real economy and trigger bubbles. In the post-industrial era, improving industrial quality and maintaining the proportion of industrial output and employment at an appropriate level, which are necessary conditions for realizing full industrialization and sustainable economic growth.

\section{References}

Acemoglu, D., \& Restrepo, P. (2018a). Low-skill and High-skill Automation. Journal of Human Capital, 12(2), 204-232. https://doi.org/10.1086/697242

Acemoglu, D., \& Restrepo, P. (2018b). Artificial Intelligence, Automation and Work. NBER Working Paper, No.24196. https://doi.org/10.3386/w24196

Baumol, W. (1967). Macroeconomics of Unbalanced Growth: The Anatomy of Urban Crisis. American Economic Review, 57(3), 415-426.

Brandt, L., Biesebroeck, J. V., \& Zhang, Y. (2012). Creative Accounting or Creative Destruction? Firm-level Productivity Growth in Chinese Manufacturing. Journal of Development Economics, 97(2), 339-351. https://doi.org/10.1016/j.jdeveco.2011.02.002

Chen, K., \& Zha, T. (2018). Macroeconomic Effects of China's Financial Policies. NBER Working Paper, No.25222. https://doi.org/10.3386/w25222

Chen, Z., He, Z., \& Liu, C. (2020). The Financing of Local Government in China: Stimulus Loan Wanes and Shadow Banking Waxes. Journal of Financial Economics, 137(1), $42-71$. https://doi.org/10.1016/j.jfineco.2019.07.009

Chenery, H. B. (1960). Patterns of Industrial Growth. American Economic Review, 50(4), 624-654.

Clark, C. (1940). The Conditions of Economic Progress. London, Macmillan.

Ebenstein, A., Harrison, A., \& McMillan, M. (2017). Why Are American Workers Getting Poorer? China, Trade, and Offshoring. Chapter 8 in L. Fontagné and A. Harrison (Eds.), The Factory-Free Economy. Outsourcing, 
Servitization, and the Future of Industry. Oxford University Press, March. https://doi.org/10.1093/acprof:oso/9780198779162.003.0009

Feenstra, R. C., Grossman, G. M., \& Irwin, D. A. (1996). The political economy of trade policy: Papers in honor of Jagdish Bhagwati. Cambridge and London, MIT Press.

Kongsamut, P., Rebelo, S., \& Xie, D. (2001). Beyond Balanced Growth. Review of Economic Studies, 68(4), 869-882. https://doi.org/10.1111/1467-937X.00193

Kuznets, S. (1971). Economic Growth of Nations. Cambridge, Mass. Harvard University Press. https://doi.org/10.4159/harvard.9780674493490

Liu, X., Mattoo, A., Wang, Z., \& Wei, S. (2020). Services Development and Comparative Advantage in Manufacturing. Journal of Development Economics, 144, 1-17. https://doi.org/10.1016/j.jdeveco.2019.102438

Nordhaus, W. D. (2008). Baumol's Diseases: A Macroeconomic Perspective. B. E. Journal of Macroeconomics, 8(1), 1-39. https://doi.org/10.2202/1935-1690.1382

Rodrik, D. (2016). Premature Deindustrialization. Journal of Economic Growth, 21(1), 1-33. https://doi.org/10.1007/s10887-015-9122-3

\section{Copyrights}

Copyright for this article is retained by the author(s), with first publication rights granted to the journal.

This is an open-access article distributed under the terms and conditions of the Creative Commons Attribution license (http://creativecommons.org/licenses/by/4.0/). 